\title{
Theoretical investigation of force acting during flanging of anisotropic sheet materials
}

\author{
Gryazev Mikhail Vasikievich \\ Rector \\ Tula State University, \\ Tula, Russia
}

\author{
Larin Sergey Nikolaevich \\ Head of department of "Mechanics of Plastic Forming" \\ Tula State University, \\ Tula, Russia
}

\author{
Pasynkov Andrey Aleksandrovich \\ Assistant professor of department of \\ "Mechanics of Plastic Forming" \\ Tula State University, \\ Tula, Russia
}

\begin{abstract}
Flanging is quite actively used in the manufacturing of workpieces with necks. Its prevalence in production explains the fact that there is a huge number of Russian and foreign researches discussing this operation, which unfortunately do not take into account the influence of the mechanical properties of the blank. Thus, the study of this process, in relation to the anisotropy, is essential. This article deals with the flanging of a sheet semi-finished workpiece with a hole made at the intermediate stage of deformation in a radial die. The research investigates the effects of such important parameters as flanging coefficient and radius of working tool curvature at the maximum force that occurs during the flanging. The obtained results of theoretical studies can be used to create new technologies for pressure treatment of sheet flange parts, the main stamping operation of which can be the flanging of flat pieces that take into account anisotropy.
\end{abstract}

Keywords- drawing, deformation, stress, deformation, force, destruction.

\section{INTRODUCTION}

One of the most commonly used methods for the manufacturing of workpieces with necks, is sheet stamping, also known as flanging, when the inner contour of the sheet blank hole is drawn by a punch into the working surface of the die. This operation is widely used at ma-chine building enterprises, which is the reason why there is a great number of Russian and foreign researches investigating it [1-4]. However, these studies do not take into account the influence of workpiece's mechanical properties, and in particular, its anisotropy [5-8]. Therefore, the study of this process, with due regard for the developing and initial anisotropy, is essential. When creating advanced technologies for stamping thinwalled flanged products by means of flanging, it is necessary to determine the power modes, maximum deformation limits, as well as the geometric dimensions of the workpiece being manufactured [9-12].

\section{RESULTS AND DISCUSSION}

Figure 1 shows the scheme of blank flanging with a round hole with a coefficient $m_{o}=r_{0} / R_{1}$ at the deformation stage, at which the forces and stresses are at maximum. During the investigated process both the growth of the hole perimeter and the increase of forming workpiece part's bending along the working contour of the die occur at the same time. Then the forming part is aligned with the cylindrical part of the die and the punch.

The material of the forming workpiece is considered incompressible and having initial anisotropy. During the flanging, it gets isotropically strengthened. For the process under investigation, the Mises-Hill yield criterion and the associated flow rule are valid. Modeling is carried out with the assumption that the stress state is plane. Friction at the edges of the tool and the workpiece is taken into account, and as well as the effect of Coulomb's law of friction.

The process under investigation was calculated using energy-force parameters estimation method, based on the simultaneous solution of approximate differential equilibrium equations and the yield criterion. Zone 1 of the blank, which is opposite the lower part of punch end, is always only slightly detached from it, and therefore, the values of the bending moment in the zone between the first and second sections of zone 2 are negligible. 


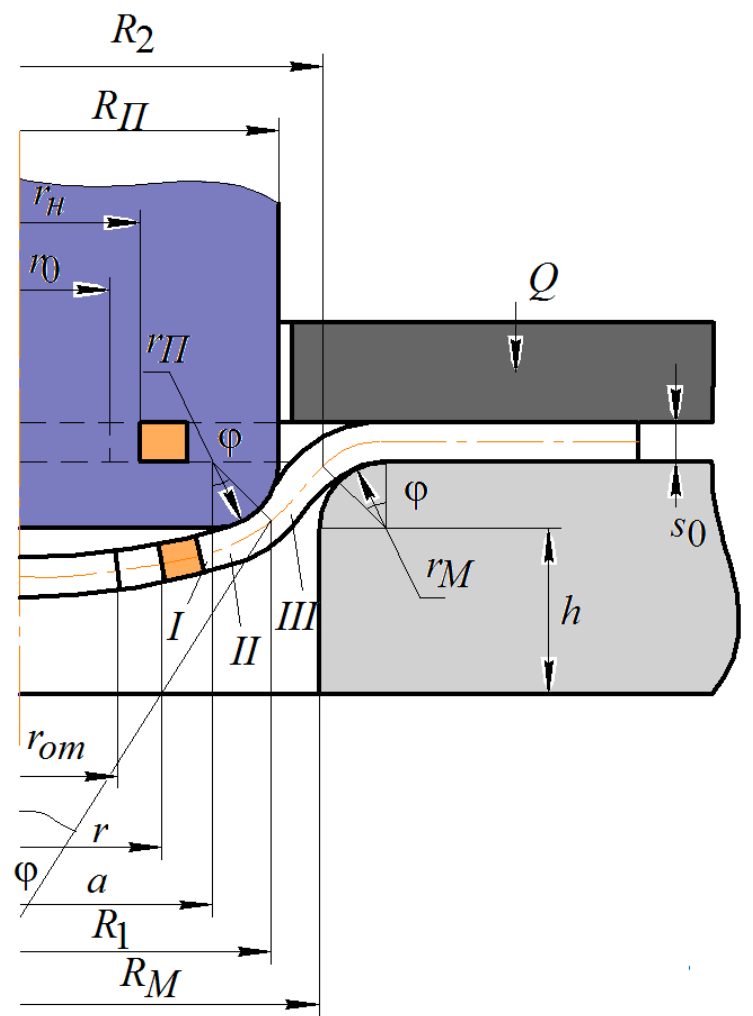

Fig. 1. Theoretical evaluation of sheet blanks flanging

There are no external stresses in the first section of blank's zone 1 , and therefore the stress state of the workpiece in this section can be calculated by solving the differential equation of equilibrium [1-4] together with the yield criterion for $r=r_{0}, \sigma_{r}=0$.

Let us calculate the state of the workpiece in the section 1 of zone 1. The rates of deformation acting in various directions on the surface along the thickness of the workpiece can be found from the correspondences presented in [3].

Taking into account the equation $\xi_{r}+\xi_{\theta}+\xi_{z}=0$ and the equation for estimation of the relationship between the rates of deformations and stresses [1-4], we obtain:

$$
\frac{d V_{r}}{d r}=\frac{V_{r}\left(\sigma_{r}+\sigma_{\theta}\right)}{\sigma_{\theta} r(1+R)-R r \sigma_{r}}-\frac{V_{r}}{r} .
$$

Taking into account the differential equation of equilibrium, after the integration let us write the formula (1) in the following form:

$$
\sigma_{r n}=\sigma_{r n-1}-\frac{r_{n}-r_{n-1}}{r_{n-1}}\left[\sigma_{r n-1}\left(1-\frac{\sigma_{r}+\sigma_{\theta}}{\sigma_{\theta}(1+R)-R \sigma_{r}}\right)-\sigma_{\theta n-1}\right] .
$$

Then, similarly, we find $\sigma_{\theta_{n}}$ from the yield criterion at $r=r_{0}, \sigma_{r}=0$. Section 2 of zone 2 interacts with the deforming tool. Due to frictional forces, the stresses act on the inner part of the workpiece in section 2 .

In order to calculate the stresses in the meridional and circumferential directions on the rounded surface of the punch (section 2), we solve the equilibrium condition together with the yield criterion at $\varphi=\varphi_{0} \quad \sigma_{r}=\left.\sigma_{r 1}\right|_{r=a}+\left.\sigma_{s}\right|_{r=a} \cdot \frac{s}{4 r_{n c}}$, where $\varphi$ is the angle determining the positions of the investigated workpiece section; $r_{n c}=r_{n}+0,5 s_{0} ; \sigma_{r 1}$ is the stress in the meridional direction acting on the surface of the oppositely located flat part of the deforming tool's end surface (section 1) and calculated at $r=a ; \sigma_{s}$ is the resistance of the material to plastic deformation with due regard for its strengthening at $r=a ; r_{n}$ is the radius of punch's rounding. We integrate the equation numerically using the method of finite differences from the boundary between the second and the first sections of the deformation center.

Section 3 of the deformation center 3 is formed without the tool force. The stress state in a conical section is found by integrating the differential equilibrium equation together with the yield criterion for $r=R_{1}$. The maximum value of the stresses formed in the dividing zone of the deformation center can be determined when $r=R_{2}$, that is, when the fragments 
of the workpiece are bent at the edge of the die. The degree of influence of this bending on $\sigma_{r}$ is calculated as follows:

$$
\begin{gathered}
\sigma_{r}=\left(\left.\sigma_{r 2}\right|_{r=R_{1}}+\left.\sigma_{s}\right|_{r=R_{1} \cdot \frac{s}{4 r_{n c}}}\right) \mid r=R_{2}+ \\
+\left.\sigma_{s}\right|_{r=R_{2}} \frac{s}{4\left(r_{M}+0,5 s_{0}\right)},
\end{gathered}
$$

where $r_{M}$ is the radius of die's rounding.

In equation (4), the value after the equal sign allows us to take into account the increase of stresses in the meridional direction, which arises when the workpiece is straightened. In this formula, the radius of the flanging hole at the moment $r_{\text {om }}$ depends on the angle, which is estimated according to punch motion value. As the punch moves, this angle changes from $\pi / 2$ at the initial forming moment to 0 , at the final moment, when the force is at its peak, i.e. the radii of the forming tool are at the same level. Together with the angle decrease, there is an increase of hole radius.

As discussed in [4], if we take into account the fact that the length of the forming workpiece does not change during the flanging, then according to the geometry dimensions it is possible to obtain an equation helping to reveal the relationship between the hole radius and the angle $\varphi$ for the moment when the gap between the tools is approximately similar to the thickness of the workpiece:

$$
r_{o m}=r_{0}+\left(r_{M}+r_{n}+s_{0}\right)[0,57+\operatorname{tg}(\varphi / 2)-\varphi],
$$

where $r_{o m}$ is the radius of the hole being flanged at the moment, reached when the angle value is $\varphi$, and $r_{0}$ is the radius of the hole in the workpiece.

At $r_{o m} \leq a$ (at the very beginning of the process):

$$
r_{o m}=r_{0}+0,57\left(r_{M}+r_{n}+s_{0}\right) \text {. }
$$

The flanging force is determined by the equation:

$$
\begin{gathered}
P_{\text {om }}=2 \pi R_{2} s\left(\left.\sigma_{r 2}\right|_{r=R_{1}}+\left.\sigma_{s}\right|_{r=R_{1}} \cdot \frac{s}{4 r_{n c}}\right){ }_{r=R_{2}}+ \\
\left.+\left.\sigma_{s}\right|_{r=R_{2}} \frac{s}{4\left(r_{M}+0,5 s_{0}\right)}\right) \cos \varphi .
\end{gathered}
$$

During the forming, the reduction of workpiece thickness and workpiece material take place at the same time. This situation has the opposite effect on the stress values in the meridional direction. As a result, we can say that workpiece thickness change, and thinning in particular, reduces the stress values in the meridional direction, and strengthening, on the contrary, increases them.
Thus, in order to take into account the strengthening of the material, we need to know the information on the deformed state of the blank.

\section{RESULTS AND DISSCUSION}

The force acting during the flanging of the blank with a round hole was estimated according to the flanging coefficient $m_{o}$ and the punch edge rounding radius $r_{n}$ for aluminum alloy Al-Mn, brass L63 and 1008. Their characteristics are presented in $[1,3,4]$.

To choose the equipment, we need to build a "force-path" diagram, which we will be created according to the abovementioned correspondences.

Hole radius in $r_{\hat{\imath} \grave{o}}$ is determined by the angle $\varphi$, which in its turn is determined by the punch motion from the initial moment of deformation. When moving it down $\varphi$ varies from $90^{\circ}$ in the beginning to $0^{\circ}$ (the working surface rounding centers of the punch and the die are aligned on one line) when the deforming tool moves at $r_{M}+r_{n}+s_{0}$ from the initial moment of deformation. At the same time the hole radius is increasing.

Figure 2 shows the correspondences that allow us to determine the influence of the relative punch path $\bar{H}=h / s_{0}$, flanging coefficient and punch working edge rounding radius on the force for Al-Mn alloy (solid line), 1008 (dashed line) and brass (centerline) respectively.

Calculations are made with $s_{0}=1.5 \mathrm{~mm} ; r_{0}=20.45 \mathrm{~mm}$; $r_{3 a 2}=81.8 \mathrm{~mm} ; R_{n}=38.65 \mathrm{~mm} ; R_{M}=40.9 \mathrm{~mm} ; r_{M}=3$ $\mathrm{mm} ; r_{n}=3 \mathrm{~mm}$.

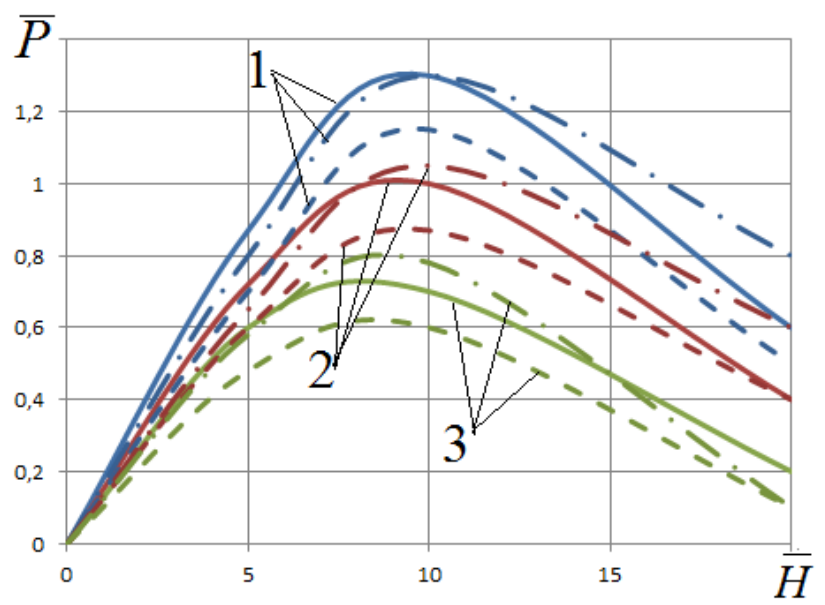

Fig. 2. The influence of $\bar{H}$ on $\bar{P}: 1-m_{o}=0.5 ; 2-m_{o}=0.6$; $3-m_{o}=0.7$

After the analysis of the figure, it can be said that the dependence of change in $\bar{P}$ during the flanging from the value of the punch working path $\bar{h}_{\Pi}$ is non-linear. We can say 
that with a decrease of the coefficient $m_{o}$ force $\bar{P}$ increases. The decrease of the coefficient $m_{O}$ from 0.5 to 0.45 occurs together with the double increase of the force.

Figure 3 shows the correspondences that allow us to evaluate the influence of the relative punch path $\bar{h}_{\Pi}=h / s_{0}$, and die working edge rounding radii on the relative force $\bar{P}$ for Al-Mn alloy (solid line), 1008 (dashed line) and brass (centerline) respectively.

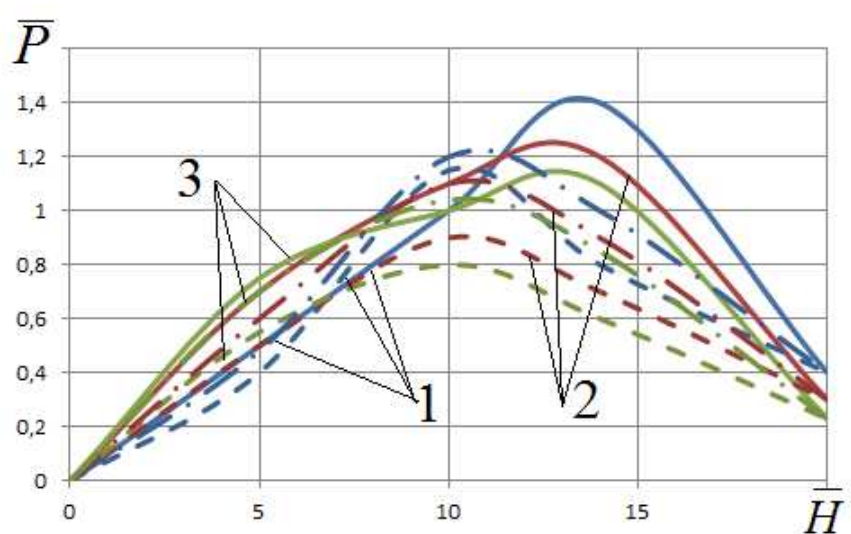

Fig. 3. The influence of $\bar{H}$ on $\bar{P}: 1-r_{M} / s_{0}=1.5$;

$2-r_{M} / s_{0}=3 ; 3-r_{M} / s_{0}=4.5$

After analyzing these dependencies, it can be concluded that with the decrease of the working edge rounding radius of the punch and the die from 4 to 1 , the relative flanging force increases by $35 \%$.

\section{CONCLUSION.}

This article presents the modeling results of sheet semifinished workpiece flanging with a hole at the intermediate stage of deformation through a radial working edge die with sheet material radius characterized by anisotropic properties. The research has investigated the influence of such parameters as the deformation degree, tool dimensions, friction parameters and clamping pressure on the flanging drawing force for various types of metals and blank dimensions. The obtained results can be used as recommendations for technological processes.

\section{Acknowledgment}

The research was carried out within the framework of RFBR grant No. 16-48-710014 and Tula region administration grant.

\section{References}

[1] E.A. Popov Fundamentals of the theory of sheet punching, Moscow: Mechanical Engineering, 1977, 278 p.

[2] V.I. Ershov, O.V. Popov, A.S. Chumadin Sheet stamping: Calculation of technological parameters, Moscow: Izd-vo MAI, 1999. 516 p.

[3] Yu.G. Nechepurenko, S.P. Yakovlev, S.S. Yakovlev Deep drawing of cylindrical products from an aniso-tropic material, Tula: Tula State University, 2000, 195 pp.

[4] O.V. Pilipenko, S.S. Yakovlev, V.I. Tregubov "Extraction with thinning of the wall of cylindrical parts from two-layer anisotropic materials", Blank production in mechanical engineering, №1, pp. 30-35, 2008.

[5] S.A. Evsyukov "Flanging the necks on workpieces that have anisotropic hardening”, Forging-stamping production, № 11, pp. 17-19, 1994.

[6] S.S. Yakovlev, V.I. Tregubov, Yu.G. Nechepurenko "Deep drawing of an anisotropic hardening material", Procurement industries, № 4, pp. 38 - 44. 2005.

[7] A. Mousavia, T. Kunzeb, T. Rochb, A. Lasagnib, A. Brosius "Deep drawing process without lubrication - an adapted tool for a stable, economic and environmentally friendly process", Procedia Engineering, Vol. 207, pp. 48-53, 2017.

[8] Jennifer Tennera, Kolja Andreasa, Adrian Radiusa, Marion Merklein "Numerical and experimental inves-tigation of a dry drawing of aluminum alloys with conventional and coated tool surface", Procedia Engineering, Vol. 207, pp. 2245-2250, 2017.

[9] Junsong Jin, Xinyun Wang Lei, Deng Jiancheng Luo “A single-step hot stamping-forging process for the aluminum alloy shell with nonuniform thickness", Journal of Materials Processing Technology, Vol. 228, pp. 170-178, February 2016.

[10] Dongbin Wei, Liang Luo, Hideki Satoc, Zhengyi Jiang, Kenichi Manabec "Simulations of hydro-mechanical deep drawing using Voronoi model and real microstructure model", Procedia Engineering, Vol. 207, pp. 1033-1038, 2017.

[11] Weiqin Tang, Shiyao Huang, Dayong Li, Yinghong Peng "Mechanical anisotropy and deep drawing behaviors of AZ31 magnesium alloy produced by unidirectional and cross rolling", Journal of Materials Processing Technology, Vol. 215, pp. 320-326, January 2015.

[12] Y. Abea, T. Ohmia, K. Moria, T. Masudab "Improvement of the formability in the deep drawing of ultra-high strength steel sheets by coating of die", Journal of Materials Processing Technology, Vol. 214, Issue 9, pp. 1838-1843, 2014. 